\title{
Hydrazine Detection during Ammonia Electro-Oxidation using an Aggregation-Induced Emission Dye
}

\section{Kumar Siddharth a, $\uparrow$, Parvej Alam ${ }^{b, \dagger}$, Md Delowar Hossain a, Ni Xie ${ }^{\text {b }}$, Gabriel Sikukuu

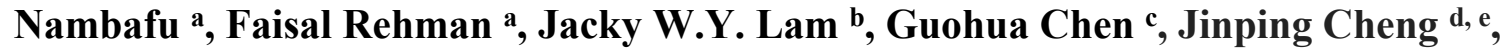 Zhengtang Luo a, Guanghao Chen f, g, Ben Zhong Tang a, b, h, *, Minhua Shao a, e, g, *}

${ }^{\text {a }}$ Department of Chemical and Biological Engineering, The Hong Kong University of Science and Technology, Clear Water Bay, Kowloon, Hong Kong

${ }^{b}$ Department of Chemistry, Hong Kong Branch of Chinese National Engineering Research Center for Tissue Restoration and Reconstruction and Institute for Advanced Study, The Hong Kong University of Science and Technology, Clear Water Bay, Kowloon, Hong Kong ${ }^{\mathrm{c}}$ Department of Mechanical Engineering, The Hong Kong Polytechnic University, Kowloon, Hong Kong

${ }^{\mathrm{d}}$ Department of Ocean Science, The Hong Kong University of Science and Technology, Clear Water Bay, Kowloon, Hong Kong

${ }^{\mathrm{e}}$ Hong Kong Branch of the Southern Marine Science and Engineering Guangdong Laboratory, The Hong Kong University of Science and Technology, Clear Water Bay, Kowloon, Hong Kong

${ }_{\mathrm{f}}^{\mathrm{f}}$ Department of Civil and Environmental Engineering, The Hong Kong University of Science and Technology, Clear Water Bay, Kowloon, Hong Kong

${ }^{g}$ Chinese National Engineering Research Center for Control \& Treatment of Heavy Metal Pollution, The Hong Kong University of Science and Technology, Clear Water Bay, Kowloon, Hong Kong

${ }^{\text {h }}$ AIE Institute, Guangzhou Development District, Huangpu, Guangzhou 510530, China

These authors contributed equally to this paper.

*Corresponding authors: kemshao@ust.hk, tangbenz@ust.hk 
Table S1. Intermediate detection techniques, pros, and cons.

\begin{tabular}{|c|c|c|c|}
\hline Technique & Reference & Pros & Cons \\
\hline ATR-SEIRAS & S1 & $\begin{array}{c}\text { Simple surface- } \\
\text { selection rule, facile } \\
\text { construction of optical } \\
\text { pathway }\end{array}$ & $\begin{array}{l}\text { Highly complicated, } \\
\text { not specific, only IR- } \\
\text { active species }\end{array}$ \\
\hline SERS & S2 & $\begin{array}{l}\text { High sensitivity, } \\
\text { precise }\end{array}$ & $\begin{array}{c}\text { Highly complicated, } \\
\text { only Raman-active } \\
\text { species }\end{array}$ \\
\hline DEMS & S3 & $\begin{array}{l}\text { Detects volatile } \\
\text { products, real-time } \\
\text { monitoring }\end{array}$ & Only gaseous species \\
\hline RRDE & S4 & $\begin{array}{l}\text { Stable current density } \\
\text { limited by mass } \\
\text { transfer }\end{array}$ & $\begin{array}{l}\text { Only indicates specific } \\
\text { redox species }\end{array}$ \\
\hline AIE-based sensing & Our study & $\begin{array}{c}\text { Convenient, specific, } \\
\text { easy structural } \\
\text { modification, solid- } \\
\text { state emission }\end{array}$ & $\begin{array}{l}\text { Can target and detect a } \\
\text { specific intermediate } \\
\text { only at a time }\end{array}$ \\
\hline
\end{tabular}

[S1] Matsui, T., Suzuki, S., Katayama, Y., Yamauchi, K., Okanishi, T., Muroyama, H. and Eguchi, K. In situ attenuated total reflection infrared spectroscopy on electrochemical ammonia oxidation over Pt electrode in alkaline aqueous solutions. Langmuir, 2015, 31(42), 11717-11723.

[S2] Vidal-Iglesias, F.J., Solla-Gullón, J., Pérez, J.M. and Aldaz, A. Evidence by SERS of azide anion participation in ammonia electrooxidation in alkaline medium on nanostructured $\mathrm{Pt}$ electrodes. Electrochem. Commun. 2006, 8(1), 102-106.

[S3] Gootzen, J.F.E., Wonders, A.H., Visscher, W., Van Santen, R.A., and Van Veen, J.A.R. A DEMS and cyclic voltammetry study of $\mathrm{NH}_{3}$ oxidation on platinized platinum. Electrochim. Acta. 1998, 43(12-13), 1851-1861.

[S4] Endo, K., Katayama, Y. and Miura, T. A rotating disk electrode study on the ammonia oxidation. Electrochim. Acta 2005 50(11), 2181-2185.

\section{Synthesis of 1,2-bis((E)-4-(1,2,2-triphenyl-vinyl)benzylidene)hydrazine (TPE-CN)2:}

To an oven dried round bottom flask sealed with rubber stopper, 4-(1,2,2-triphenylvinyl)phenol $(1.42 \mathrm{mmol})$ and anhydrous hydrazine $(0.65 \mathrm{mmol})$ were added, followed by the addition of dry methanol $(10 \mathrm{~mL})\left(\right.$ Scheme S1). The reaction mixture was refluxed at $70{ }^{\circ} \mathrm{C}$ for $12 \mathrm{~h}$. Then, the mixture evaporated under reduced pressure to afford the crude product which was further purified 
by column chromatography using ethyl acetate/hexane mixture as an eluent to give a solid product in $50 \%$ yield.<smiles>CCC(N)=O</smiles>

Scheme S1. Synthetic route to 1,2-bis((E)-4-(1,2,2-triphenyl-vinyl)benzylidene)hydrazine (TPE$\mathrm{CN})_{2}$.

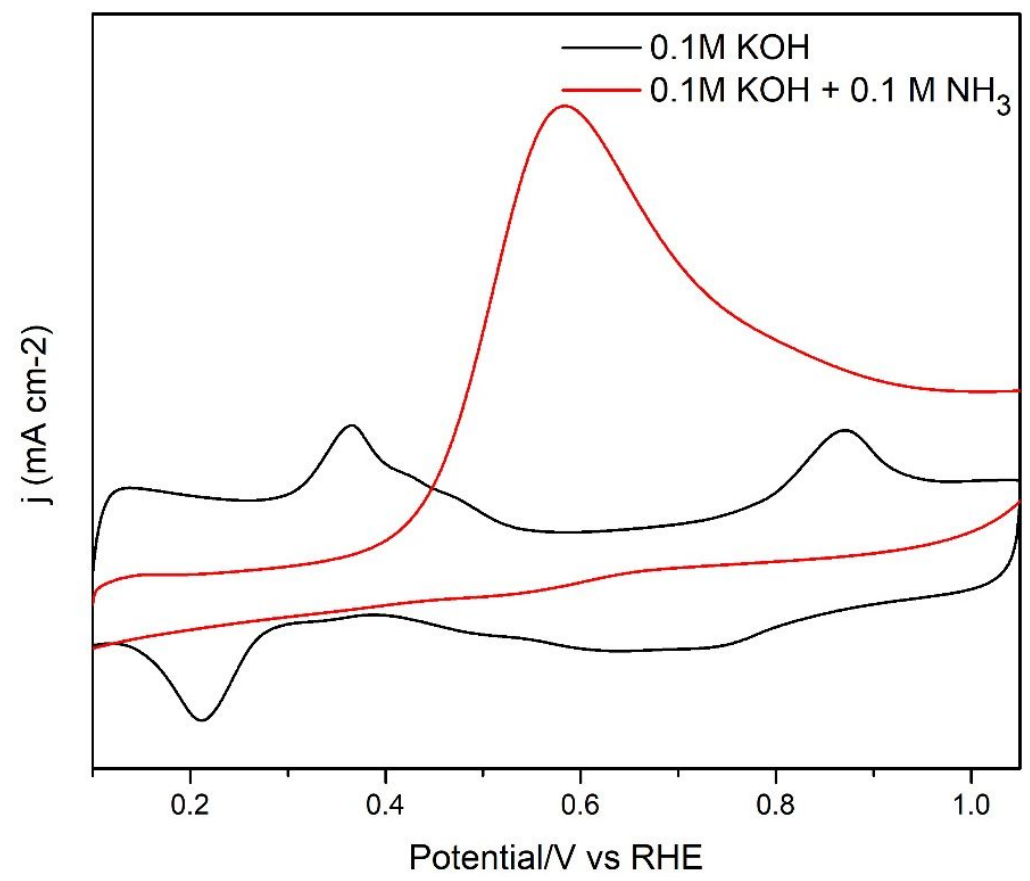

Figure S1. CVs of Pt/C deposited on GC in $0.1 \mathrm{M} \mathrm{KOH}$ and $0.1 \mathrm{M} \mathrm{KOH}+0.1 \mathrm{M} \mathrm{NH}_{3}$ solutions, respectively from $0.1 \mathrm{~V}$ to $1.1 \mathrm{~V}$ (vs RHE) at $50 \mathrm{mV} \mathrm{s}^{-1}$. 


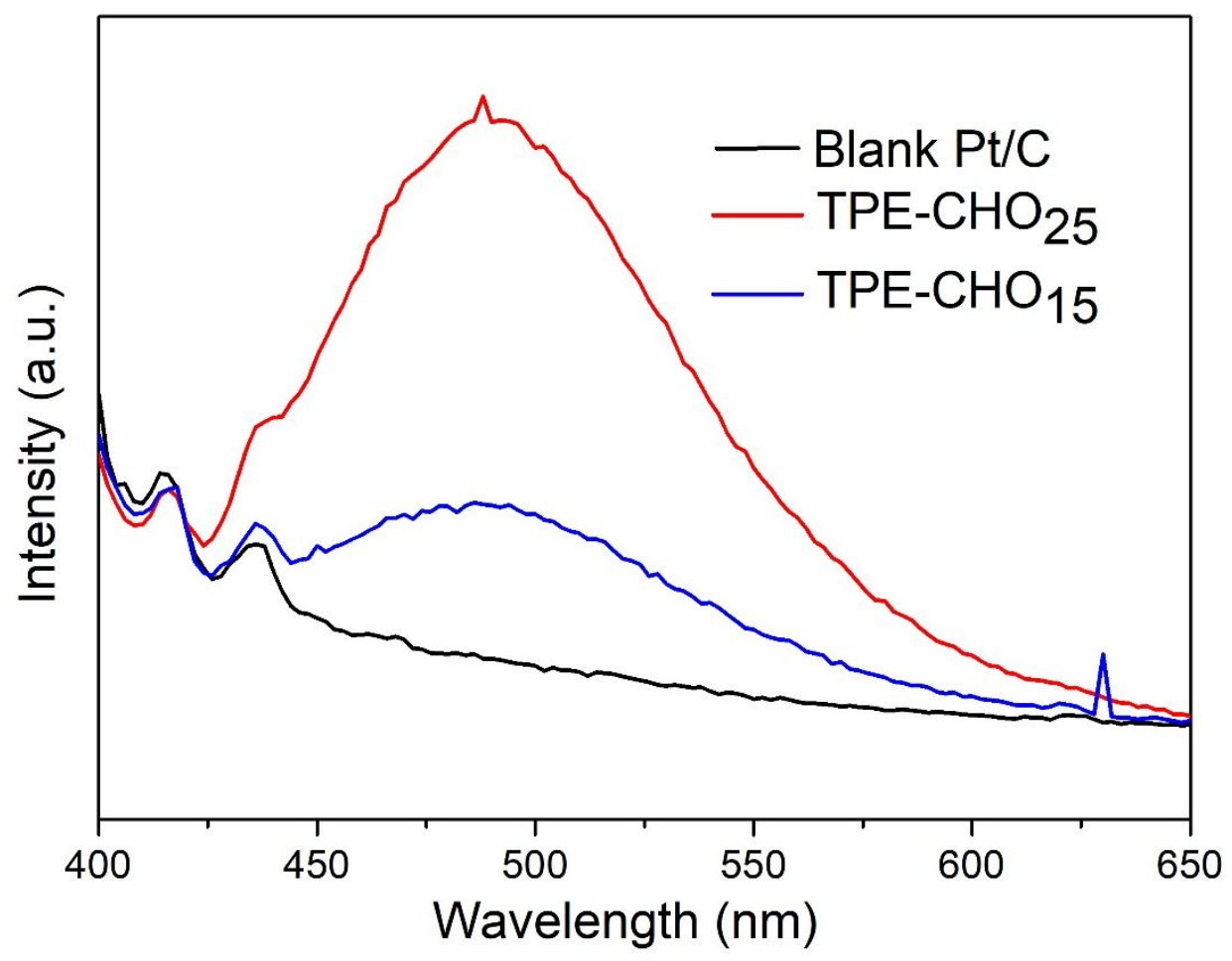

Figure S2. PL spectra in THF/water mixture with $90 \%$ of water fractions for blank $\mathrm{Pt} / \mathrm{C}$, TPE- $\mathrm{CHO}_{25}$ (25 $\mu \mathrm{l}$ from stock solution) and $\mathrm{TPE}^{-\mathrm{CHO}_{15}}$ (15 $\mu \mathrm{l}$ from stock solution), respectively keeping the electrocatalyst loading same $\left(20 \mu \mathrm{g} \mathrm{cm}^{-2}\right)$. 


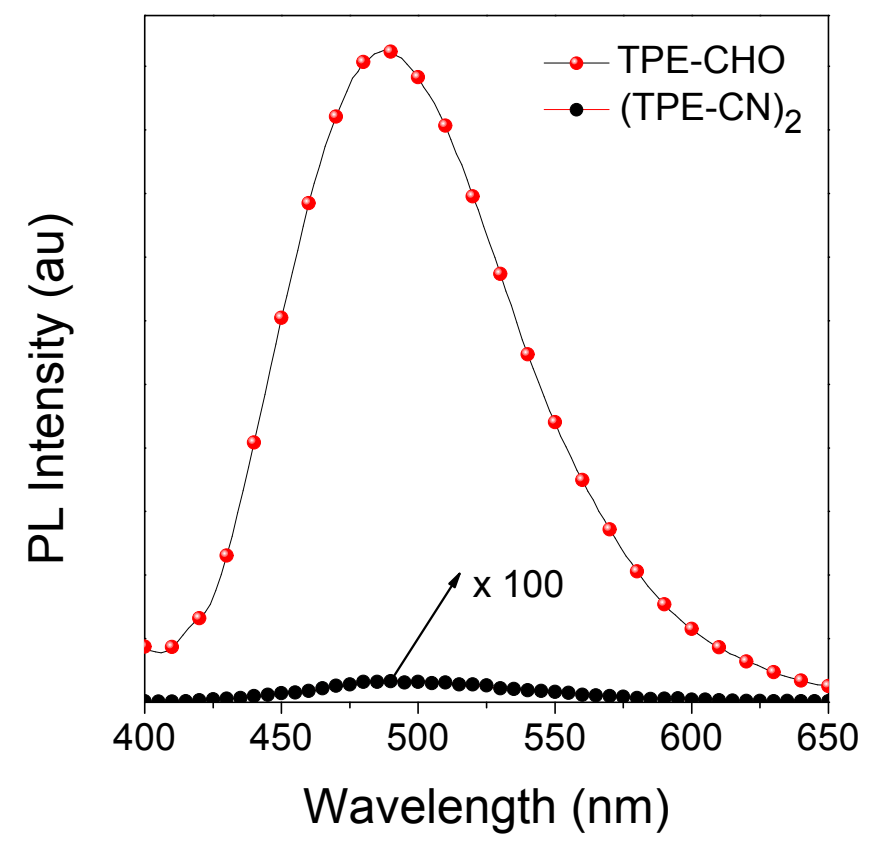

Figure S3. Photoluminescence spectra of TPE-CHO and $(\mathrm{TPE}-\mathrm{CN})_{2}$ in the solid state, $\lambda_{\mathrm{ex}}=380$ $\mathrm{nm}$. 


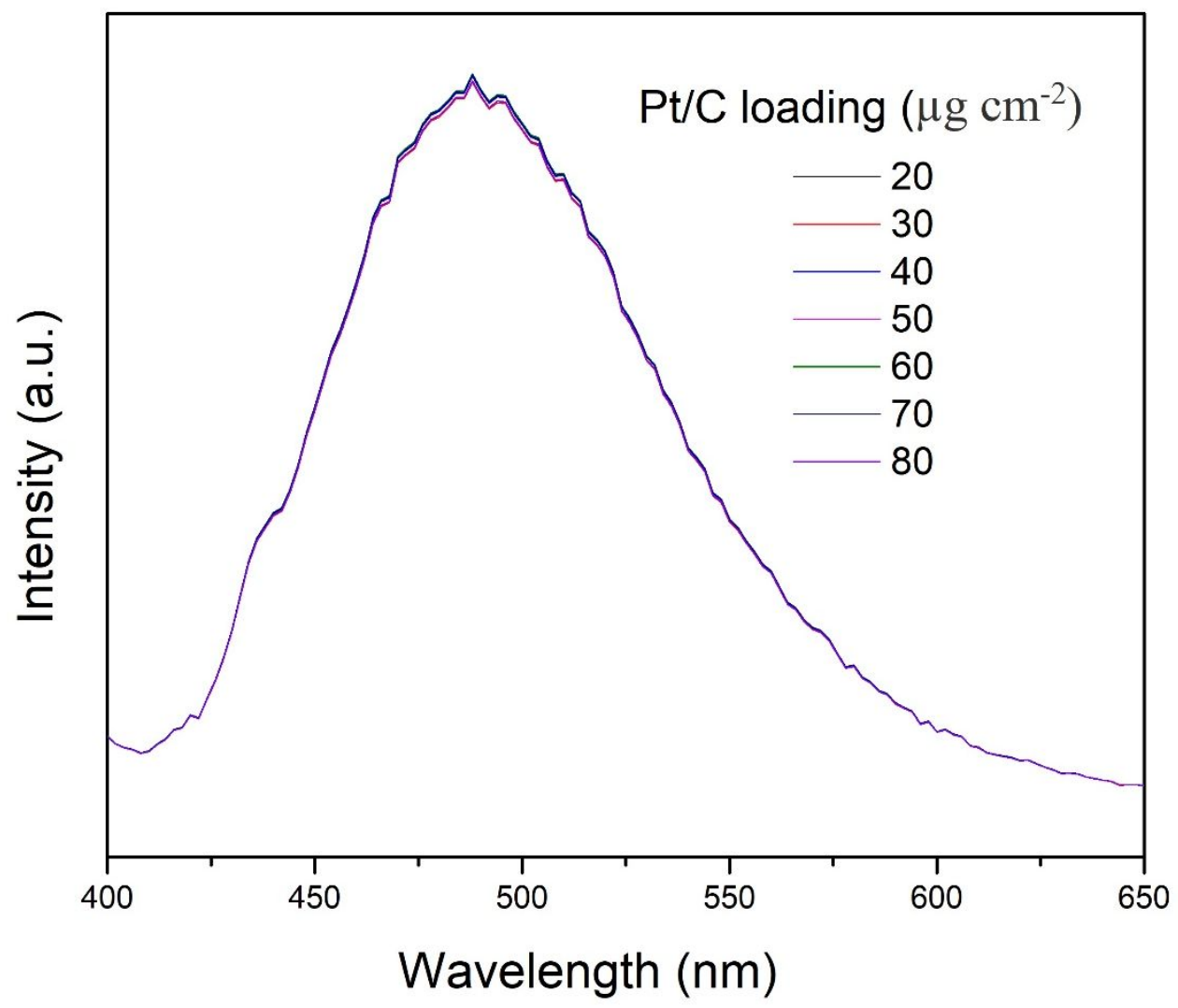

Figure S4. PL spectra in THF/water mixture with $90 \%$ of water fractions for the extracted product in $0.1 \mathrm{M} \mathrm{KOH}$ for different Pt/C loading on working electrode $(20,30,40,50,60,70$, and $80 \mu \mathrm{g}$ $\mathrm{cm}^{-2}$ ), keeping AIE concentration same as TPE- $\mathrm{CHO}_{25}$ for all cases. 
TPE-CHO: ${ }^{1} \mathrm{H}$ NMR (400 MHz, $\left.\mathrm{CDCl}_{3}\right) \delta 9.91(\mathrm{~s}, 1 \mathrm{H}), 7.63(\mathrm{~d}, J=8.2 \mathrm{~Hz}, 2 \mathrm{H}), 7.27(\mathrm{~s}, 1 \mathrm{H})$, $7.20(\mathrm{~d}, J=8.1 \mathrm{~Hz}, 2 \mathrm{H}), 7.13(\mathrm{dd}, J=6.3,3.6 \mathrm{~Hz}, 9 \mathrm{H}), 7.07-6.96(\mathrm{~m}, 6 \mathrm{H}), \mathrm{HRMS}, m / z:\left([\mathrm{M}]^{+}\right)$, calculated 360.1514, found, 360.1517 .

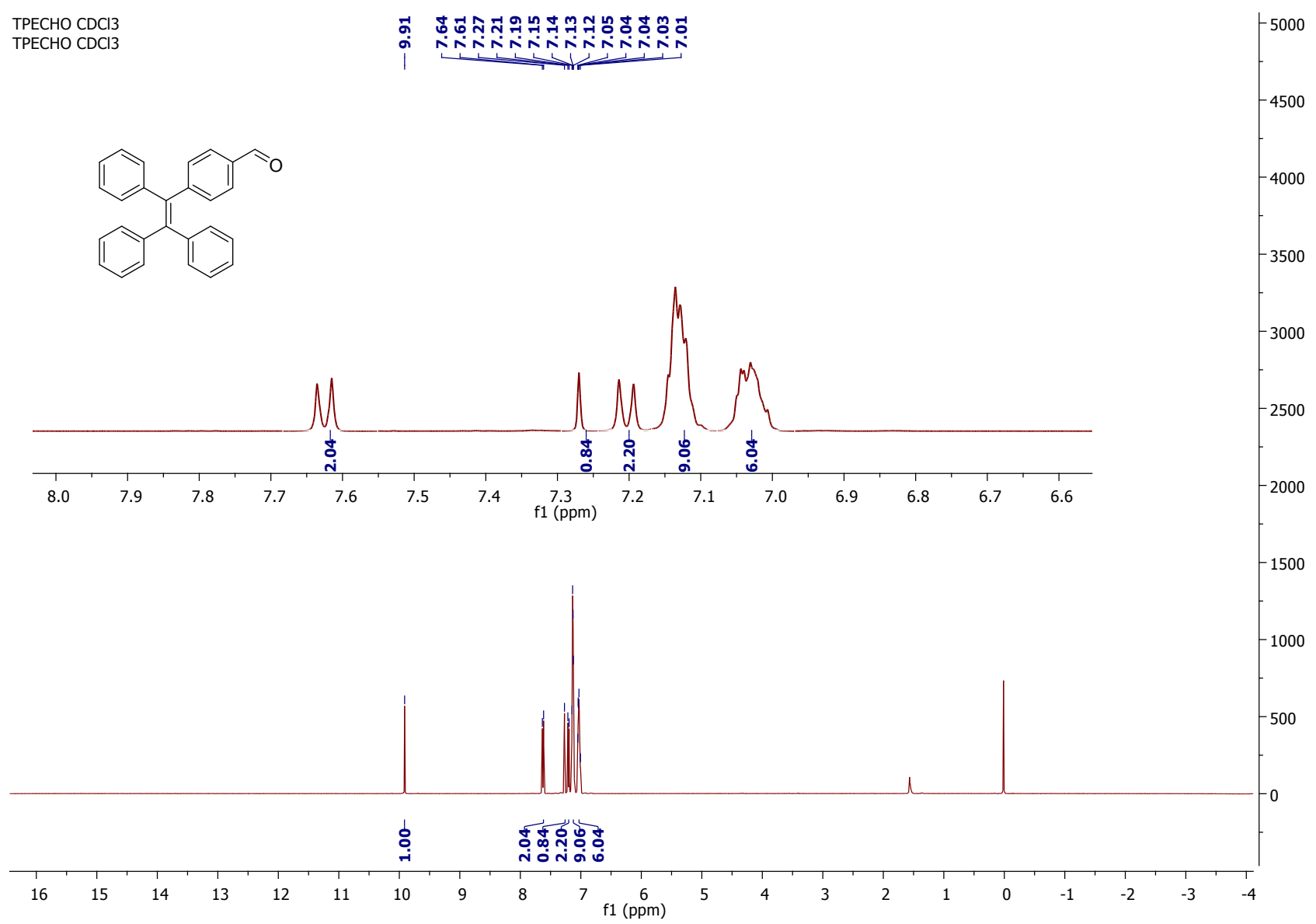

Figure S5. ${ }^{1} \mathrm{H}$ NMR spectra of TPE-CHO in $\mathrm{CDCl}_{3}$. 


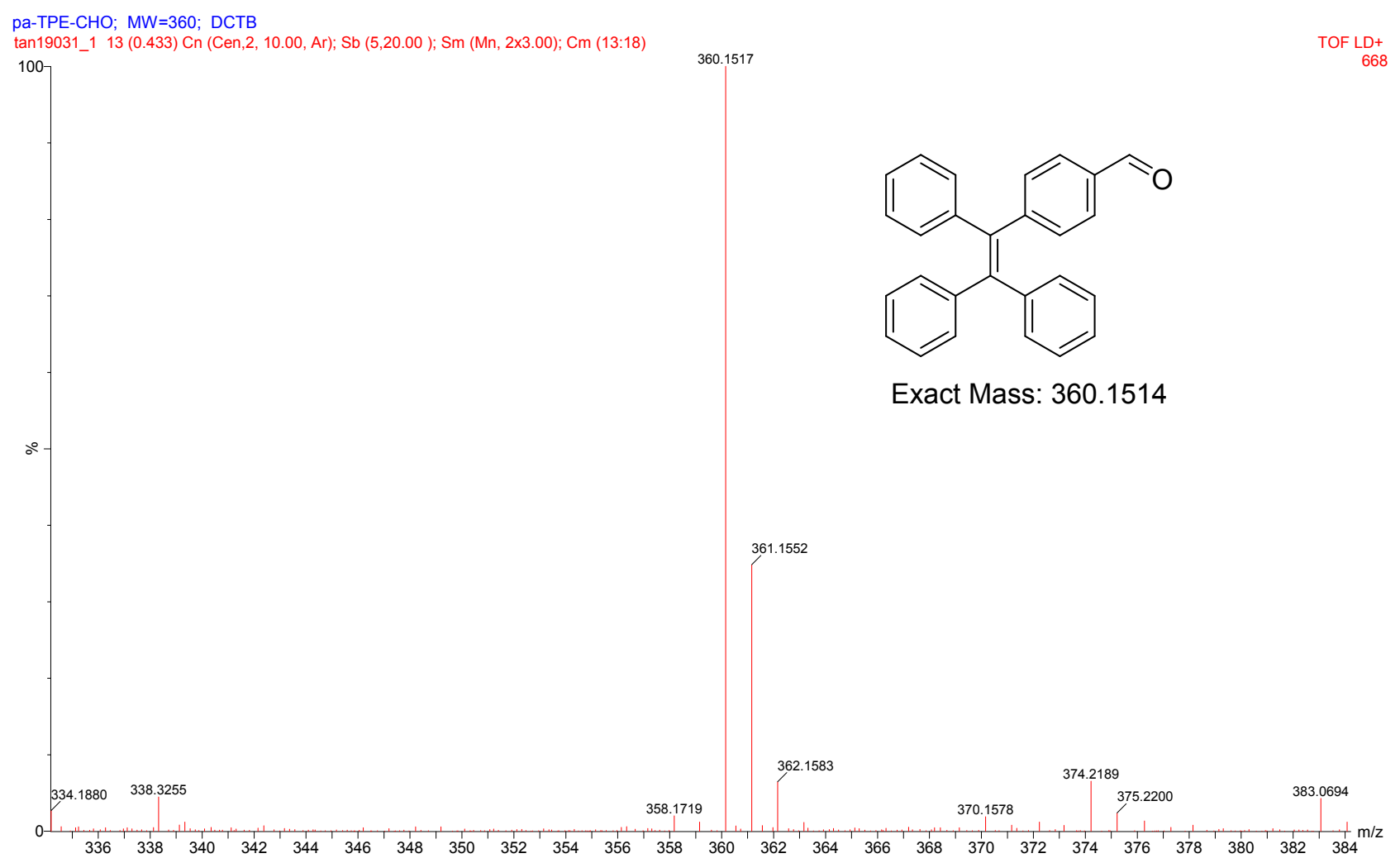

Figure S6. High-resolution MS of TPE-CHO in MALDI-TOF mode. 
$\left(\right.$ TPE-CN) $2:{ }^{1} \mathrm{H}$ NMR $\left(400 \mathrm{MHz}, \mathrm{CDCl}_{3}\right) \delta(\mathrm{ppm}):{ }^{1} \mathrm{H}$ NMR $(400 \mathrm{MHz}, \mathrm{CDCl} 3) \delta 8.57(\mathrm{~s}, 2 \mathrm{H})$, $7.58(\mathrm{~d}, \mathrm{~J}=8.2 \mathrm{~Hz}, 4 \mathrm{H}), 7.12(\mathrm{dd}, \mathrm{J}=9.1,4.6 \mathrm{~Hz}, 20 \mathrm{H}), 7.08-6.96(\mathrm{~m}, 12 \mathrm{H}), \mathrm{HRMS}, \mathrm{m} / z$ : $\left([\mathrm{M}+\mathrm{H}]^{+}\right)$, calculated 717.3270, found, 717.3077 .

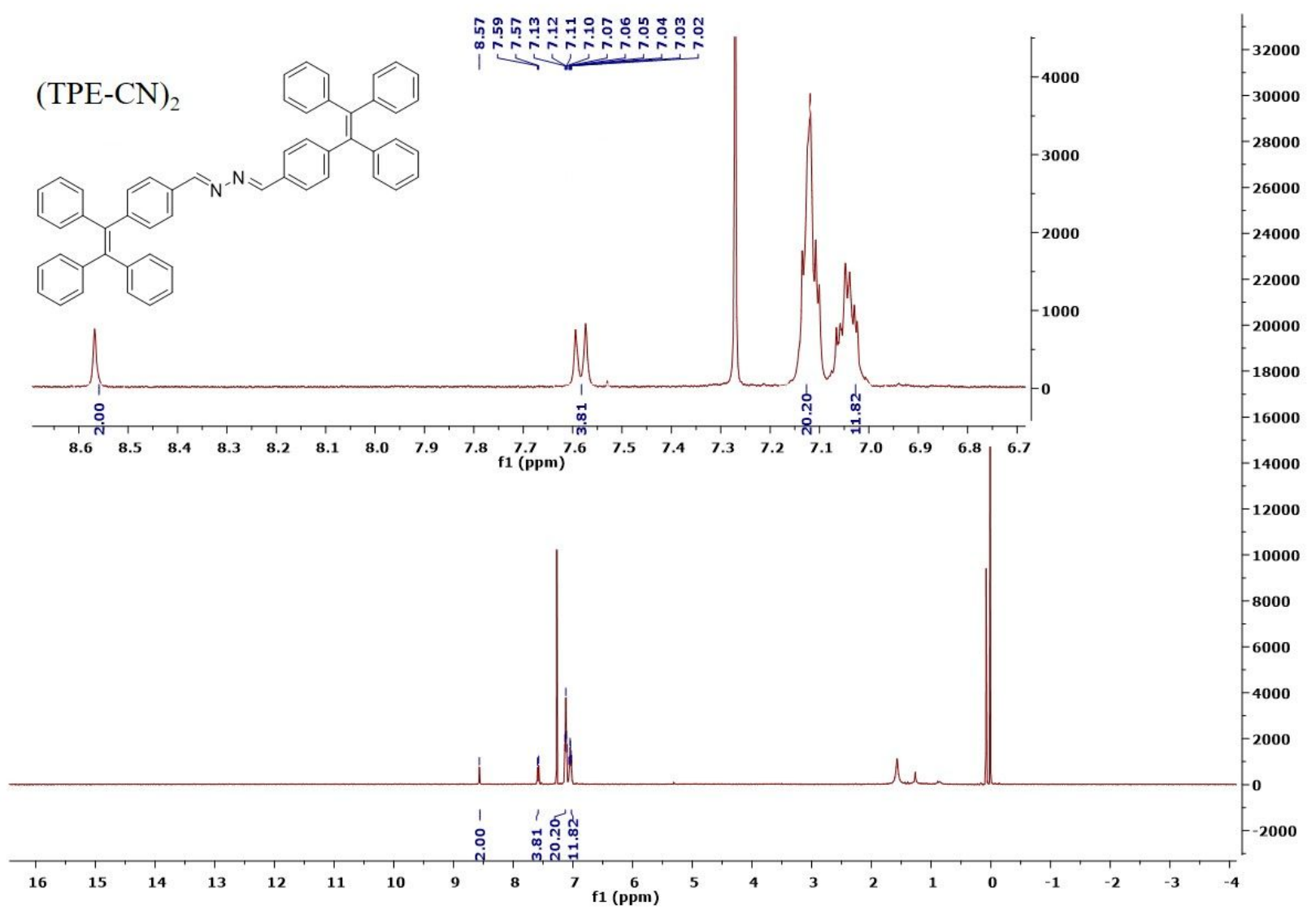

Figure S7. ${ }^{1} \mathrm{H}$ NMR spectra of $(\mathrm{TPE}-\mathrm{CN})_{2}$ in $\mathrm{CDCl}_{3}$. 


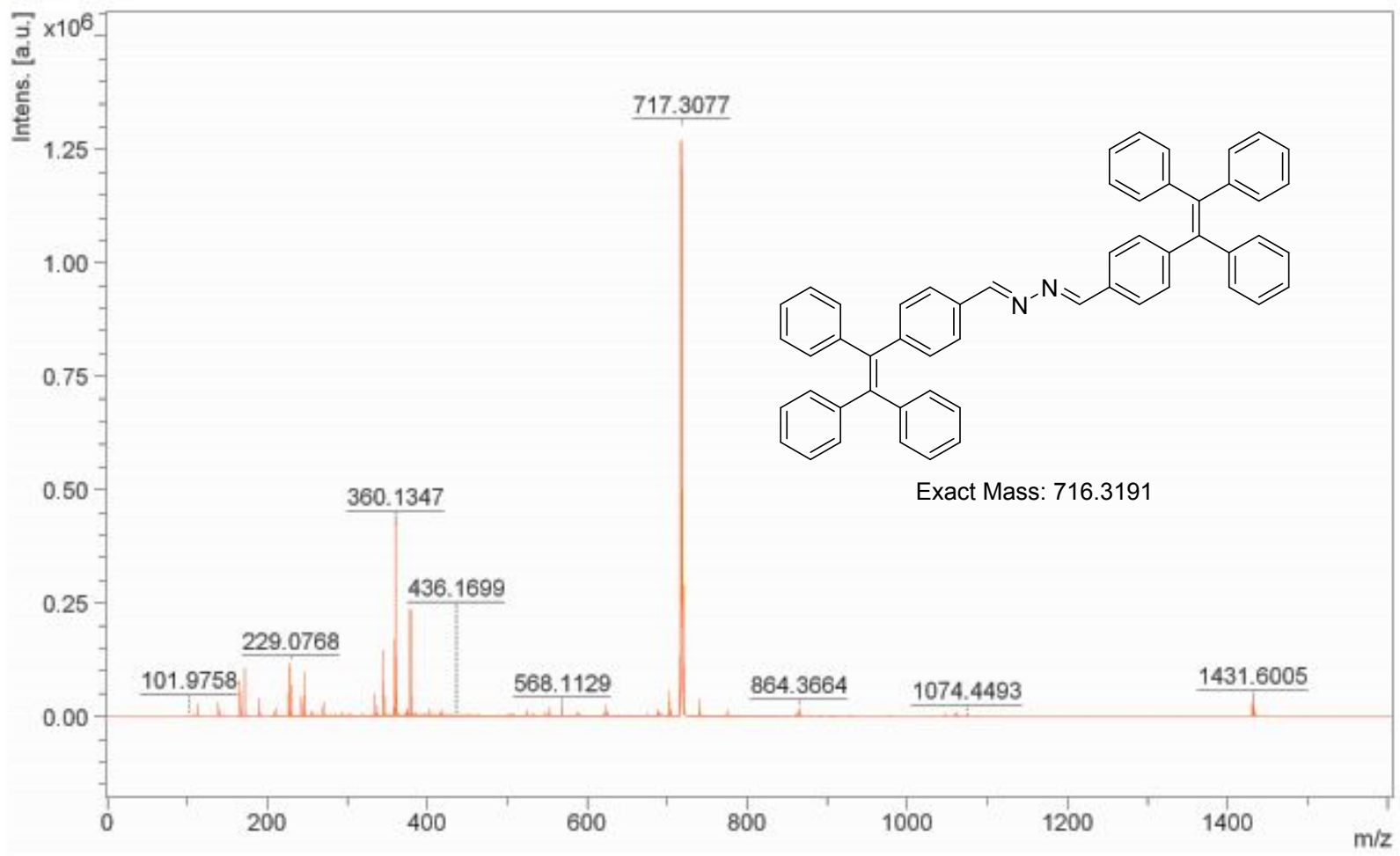

Figure S8. High-resolution MS of $(\mathrm{TPE}-\mathrm{CN})_{2}$ in MALDI-TOF mode. 


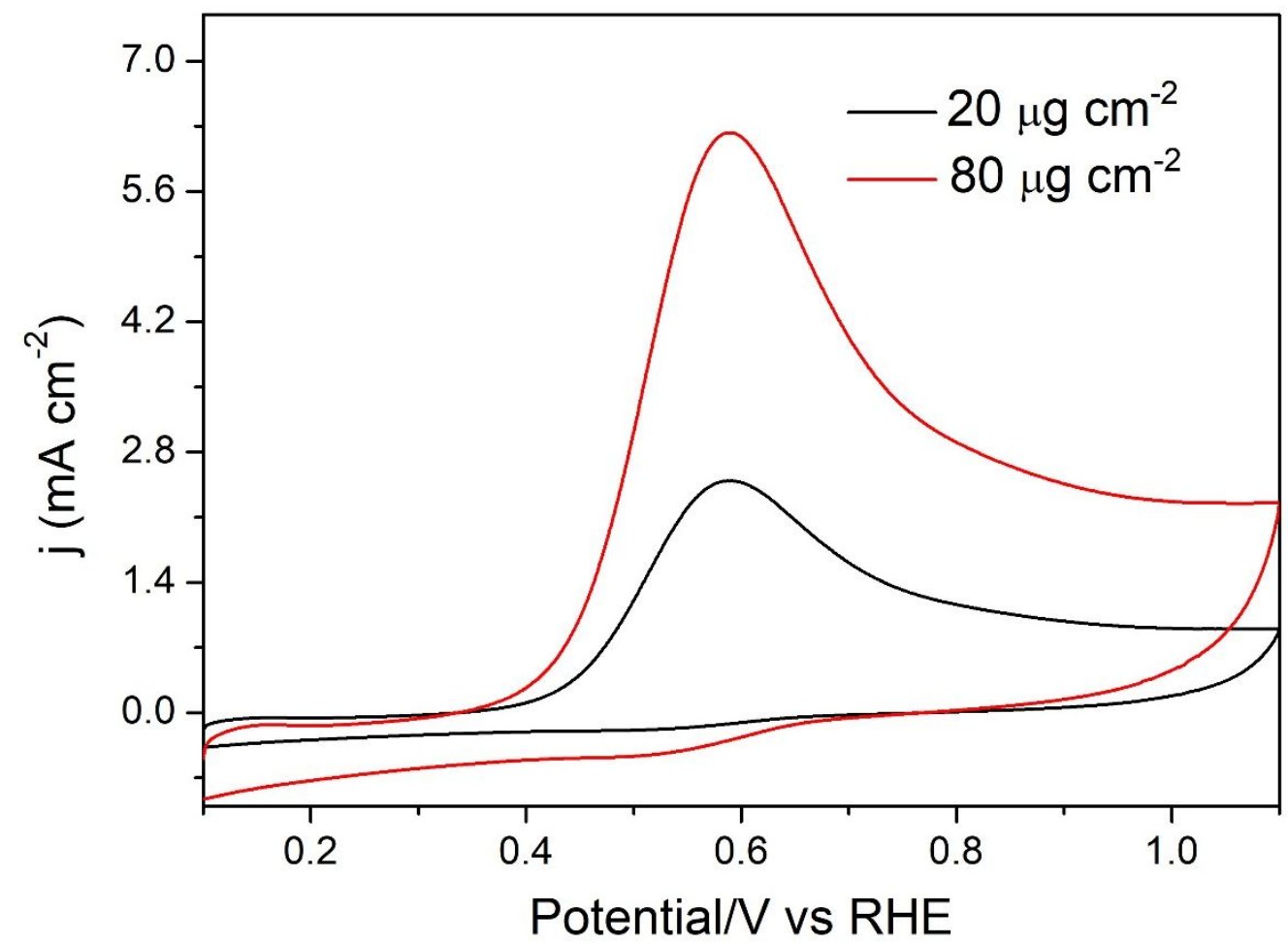

Figure S9. Corresponding CVs in $0.1 \mathrm{M} \mathrm{KOH}+0.1 \mathrm{M} \mathrm{NH}_{3}$ solution from $0.1 \mathrm{~V}$ to $1.1 \mathrm{~V}$ (vs RHE) at $50 \mathrm{mV} \mathrm{s}^{-1}$ scan rate for two different Pt/C loading $\left(20 \mu \mathrm{g} \mathrm{cm}^{-2}\right.$ and $\left.80 \mu \mathrm{g} \mathrm{cm}^{-2}\right)$, keeping TPE concentration same.

\section{Selectivity tests for $\mathrm{N}_{2} \mathrm{H}_{4}$ :}

During AOR, three possible interfering species can cause PL intensity change such as $\mathrm{NH}_{3}, \mathrm{~N}_{2} \mathrm{H}_{4}$ and $\mathrm{N}_{2} \mathrm{H}_{2}$. We have recorded PL spectra of TPE-CHO in the presence of $\mathrm{NH}_{3}$ and $\mathrm{N}_{2} \mathrm{H}_{4}$. Addition of 1 equivalent $\mathrm{NH}_{3}$ to the methanol solution of TPE-CHO produced no observable change, however, 0.37 equivalent $\mathrm{N}_{2} \mathrm{H}_{4}$ gave $\sim 184$-fold quenched emission (Figure S10). This data supports that the TPE-CHO is selective for $\mathrm{N}_{2} \mathrm{H}_{4}$ in $\mathrm{AOR}$ reaction and $\mathrm{NH}_{3}$ is eliminated.

It is generally known that $\mathrm{N}_{2} \mathrm{H}_{2}$ is unstable and readily reacts with itself to quickly form $\mathrm{N}_{2} \mathrm{H}_{4}$ and $\mathrm{N}_{2}$ gas [S5]. Additionally, $\mathrm{N}_{2} \mathrm{H}_{2}$ is not known to react with $\mathrm{CHO}$ functional group. So, we believe, its effect towards PL intensity is minimal. Furthermore, we conducted DFT calculations for both 
$\mathrm{N}_{2} \mathrm{H}_{4}$ and $\mathrm{N}_{2} \mathrm{H}_{2}$ adsorbed on Pt surface and found the following adsorption energies for the most stable configurations as shown in Table S2.

Table S2. Adsorption energies of intermediates on Pt (111) surface.

\begin{tabular}{|c|c|}
\hline Intermediate & Adsorption energy (in eV) \\
\hline $\mathrm{N}_{2} \mathrm{H}_{4}$ & -1.929 \\
\hline $\mathrm{N}_{2} \mathrm{H}_{2}$ & -0.523 \\
\hline
\end{tabular}

As elucidated in Table $\mathrm{S} 2, \mathrm{~N}_{2} \mathrm{H}_{4}$ has stronger adsorption compared to $\mathrm{N}_{2} \mathrm{H}_{2}$, thus will possess the ability of more reaction with the already deposited TPE-CHO on glassy carbon electrode, therefore giving the desired reaction. Henceforth, $\mathrm{N}_{2} \mathrm{H}_{2}$ effect towards PL intensity can be eliminated, thus leaving hydrazine $\left(\mathrm{N}_{2} \mathrm{H}_{4}\right)$ as the species detected."

[S5] Wiberg, Nils; Holleman, A. F.; Wiberg, Egon, 1.2.7 Diimine $\mathrm{N}_{2} \mathrm{H}_{2}$ [1.13.17] eds. 2001 Inorganic Chemistry. Academic Press. pp. 628-632. ISBN 978-0123526519.

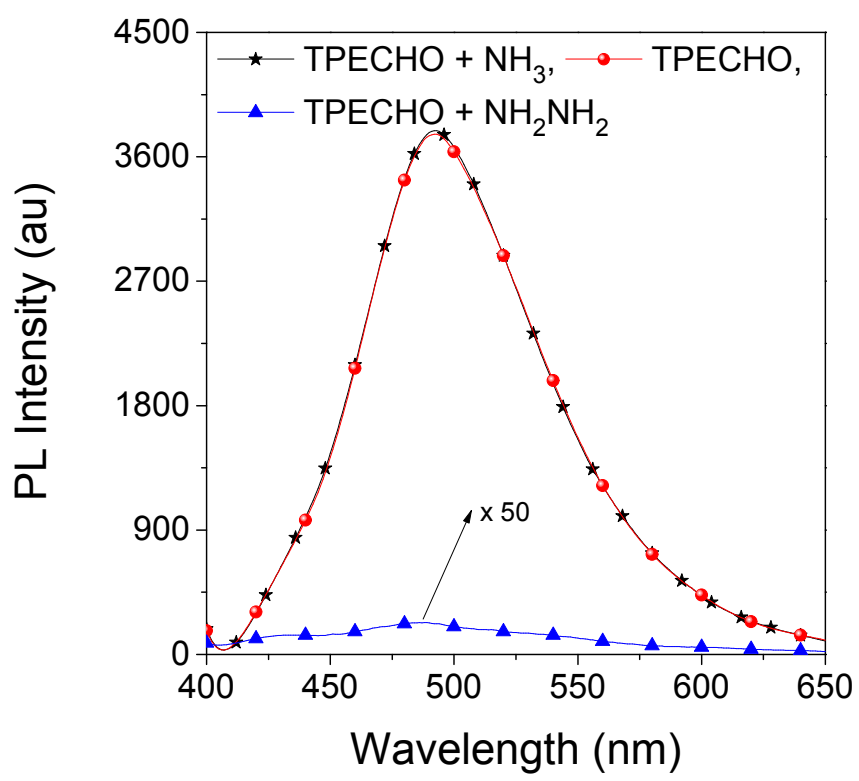

Figure S10. Photoluminescence spectra of TPE-CHO $\left(f_{\mathrm{w}}=90 \%\right)$ in presence of $\mathrm{NH}_{3}$ (1 equivalent) and $\mathrm{N}_{2} \mathrm{H}_{4}(0.37$ equivalent). All the samples were kept at room temperature for $2 \mathrm{~h}$ before the PL measurement, $\lambda_{\mathrm{ex}}=380 \mathrm{~nm}$. 


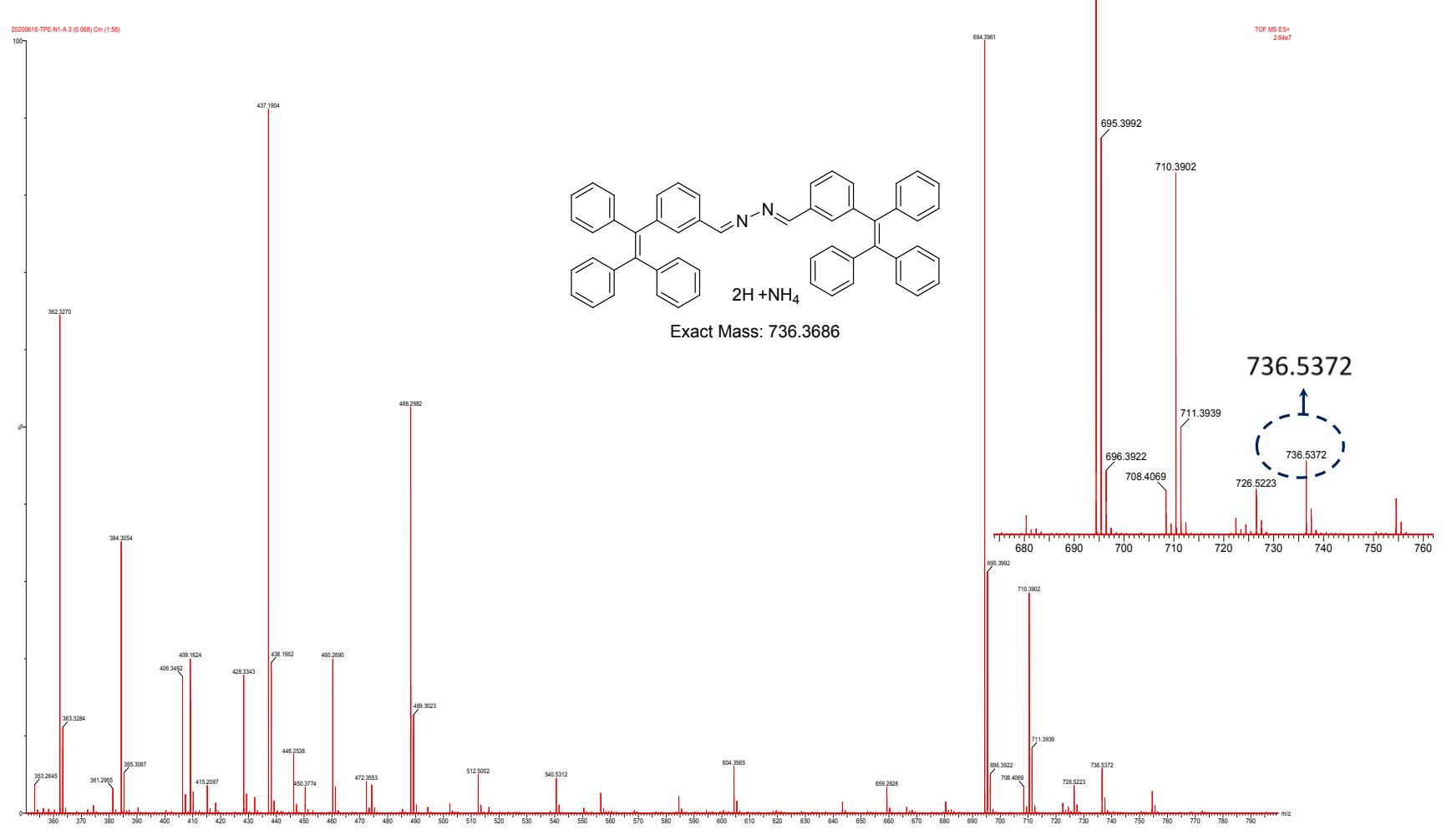

Figure S11. High-resolution MS in MALDI-TOF mode of product formed for $\mathrm{Pt} / \mathrm{C}$ loading of 20 $\mu \mathrm{g} \mathrm{cm}^{-2}$. 


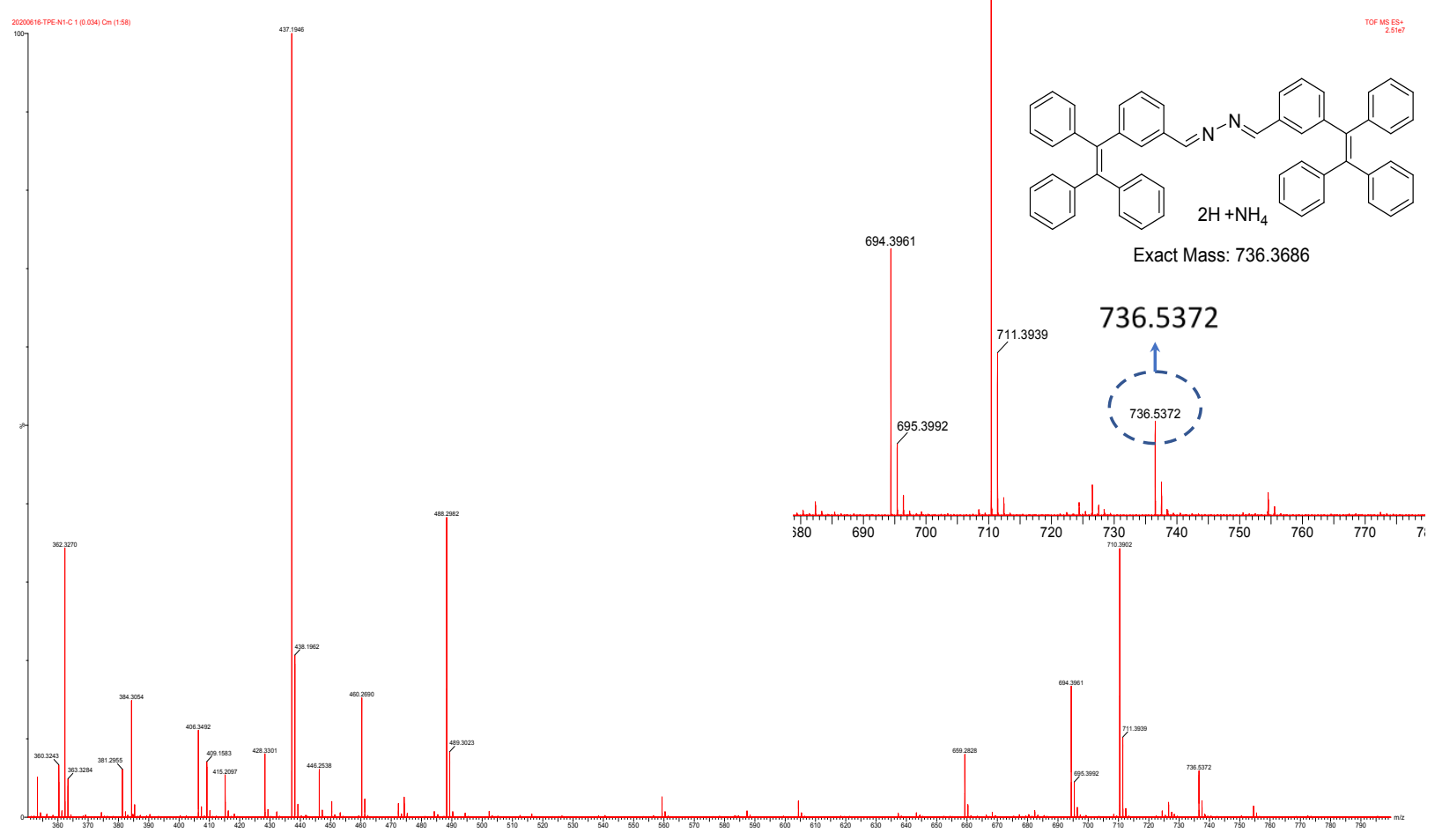

Figure S12. High-resolution MS in MALDI-TOF mode of product formed for Pt/C loading of 50 $\mu \mathrm{g} \mathrm{cm}^{-2}$. 